\title{
Crisis Management and Recovery from the Damage to the Laboratory Animal Production Facility due to the Great East Japan Earthquake
}

\author{
Takuya IKEDA \\ Charles River Laboratories Japan, I1F INNOTECH Bldg., 3-17-6 Shin-Yokohama, \\ Kohoku-ku, Yokohama, Kanagawa 222-0033, Japan
}

\begin{abstract}
Charles River Laboratories Japan produces laboratory animals, mainly mice and rats. In its history, we have experienced many crises such as mass food poisoning of staff and contamination of animals. However, we overcame these crises, accomplishing our corporate missions to secure steady supply of healthy animals. Under such circumstances, in 2008, we faced an unprecedented crisis involving a novel influenza possibly becoming pandemic. Therefore, we prepared a Crisis Management Plan (CMP) and Business Continuity Plan (BCP) to avoid the worst case scenario. Fortunately, the novel influenza did not develop into a pandemic and no major problems occurred in production of our laboratory animals. In March 2011, our Tsukuba Breeding Center was struck by the Great East Japan Earthquake. Many cages fell from racks, and consequently, 14,000 mice and rats were euthanized. Moreover, this animal production facility experienced not only blackouts and water outage but also various maintenance problems. After triage of the animals, almost half of the animals kept were eventually lost. However, we recovered and resumed shipment of animals two weeks after the disaster by utilizing the CMP and BCP we initially created as a countermeasure against novel influenza. After two months, our production volume returned to normal except for two strains. I sincerely hope this review, which highlights our experience and related issues, will be a useful resource in regard to crisis management for people who are engaged in laboratory animal care and use.
\end{abstract}

Key words: animal breeding facility, crisis management, earthquake, pandemic

\section{Introduction}

Laboratory animal production facilities are required to maintain and control the health of animals used for research and experiments even in emergencies such as disasters. Hence, laboratory animal breeders' biggest commitment is to produce healthy animals that satisfy users' requirements and to surely deliver those animals. To do so, laboratory animal breeders work hard to fulfill their responsibilities in their daily production activities.

The Tsukuba Breeding Center (TBC) of Charles River Laboratories Japan (CRLJ), located in Ishioka, Ibaraki, Japan, was struck by the Great East Japan Earth-

(Received 25 October 2011 / Accepted 7 November 2011)

Address corresponding: T. Ikeda, Charles River Laboratories Japan, 11F INNOTECH Bldg., 3-17-6 Shin-Yokohama, Kohoku-ku, Yokohama, Kanagawa 222-0033, Japan

(C) 2012 Japanese Association for Laboratory Animal Science 
quake (intensity 6 lower) in March 2011. Many animal cages fell from racks in breeding rooms, and a lot of animals were euthanized. Moreover, lifelines needed to maintain the animals such as electricity, drinking water, and fuel were shut off, causing great concerns about facility survival. This was the first large-scale disaster for laboratory animal production facilities in Japan. However, in spite of the great loss of animals, the facility retuned to its normal production volume after two months.

CRLJ was established as a laboratory animal breeder in 1972, having four laboratory animal production facilities and providing rats and mice for the purpose of experiments in medicine and bioscience. In its long history, CRLJ has experienced several crises such as the sudden absence of many staff due to food poisoning and breeding room closure because of contamination. In 2008 , these experiences were utilized in management of a pandemic crisis involving a novel influenza that originated from a highly pathogenic bird flu. At that time, we took appropriate measures based upon past crisis experiences. However, a great earthquake is an unprecedented disaster. We encountered unexpected situations, noticing new findings in the actual disaster. Still, our Crisis Management Plan (CMP) and Business Continuity Plan (BCP) were utilized considerably in recovery from the disaster and devising countermeasures against earthquakes. Hence, I consider the experiences and lessons learned at the TBC to be a good reference for crisis management for a lot of laboratory animal-related workers, and the present report highlights our crisis management measures and new findings in an actual disaster.

\section{Past Experiences and Measures}

\section{Food poisoning}

The staff of the Hino Breeding Center (located in Hino-machi, Gamo-gun, Shiga, Japan) of CRLJ suffered food poisoning caused by lunches delivered by a local caterer. In 1998, forty percent of the staff showed symptoms of diarrhea and vomiting. Some of them could not work for as long as 14 days. In some breeding rooms, animal care was maintained by only half of the staff, which caused big problems for normal animal care operations. Since then, CRLJ has established and utilized internal rules for emergencies such as having at least two caterers in each facility and procedures for cases in which many staff are unable to work.

\section{Contamination}

CRLJ's Atsugi Breeding Center (located in Atsugi, Kanagawa, Japan) had cases of Mycoplasma pulmonis contamination in rats in 1996, Streptococcus aureus contamination in immunodeficient mice in 2001 and Pasteurella pneumotropica contamination in rats in 2004. The breeding rooms for these animals were closed, and all the animals were euthanized. Some cases of contamination were found at sites receiving delivery of animals. Our initial response and customer communication were a little confused. In addition, investigation of the contamination did not identify sources or routes of the contamination. Unlike laboratory animal facilities for research and experiments, breeding facilities never introduce animals other than foundation stock. Therefore, most contamination cases are considered to be caused by humans or items brought from outside of the facilities. Learning from the past contamination cases, CRLJ established strict Sanitation Guidelines (Fig. 1) in 1997 to ensure prevention of contamination, stipulating rules for accepting visitors to our breeding centers, access limits for breeding rooms, and movement restriction between offices and breeding rooms. In addition, CRLJ introduced new work clothes incorporating a ventilation system (Fig. 2), a HEPA filter system for exhaled air of the staff, as a measure to prevent the possibility of contamination caused by animal care staff. To enhance the awareness of sanitary management of on-site animal care staff and provide continuous education for them, a team to conduct small group activities, called Biosecurity Team, was set up in each breeding center. These activities have provided training to our staff and the sanitation level has improved. Moreover, CRLJ established an Internal Audit System, Internal Emergency System and External Communication System to provide our users with rapid and accurate information.

\section{Countermeasures against novel influenza}

Since 2004, human cases and fatal cases of highlypathogenic bird flu have been reported in several countries [12], and Japanese government agencies have for- 
- Charter of Sanitation

- Sanitation Guidelines

1. Sanitation management for employees

- Personal sanitation including family

- Animal keeping regulation at home

2. Sanitation management of breeding facility

- Carry-on restrictions of materials \& animals

- Prevention of invasion of wild mice $\&$ insects

- Personal movement regulations for Bio-security

- Sanitary management

- Organization and person in charge

- Education and training

- SOP

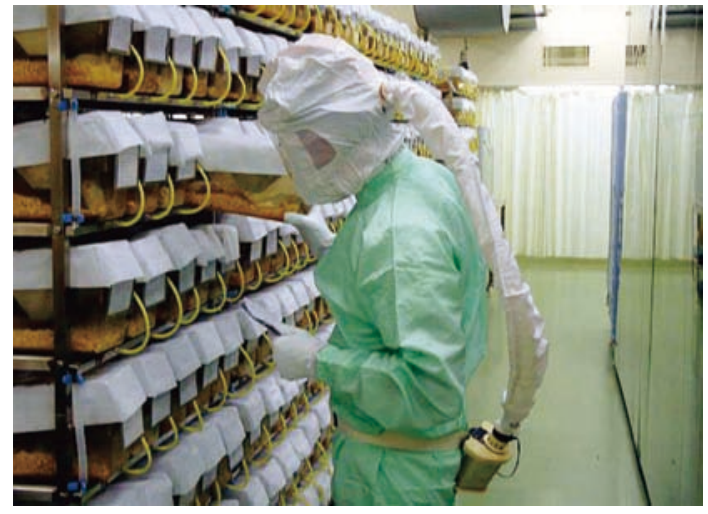

Fig. 2. Daily animal care by an animal care staff member wearing a ventilation hood system with a HEPA filter unit.

Fig. 1. Content of the CRLJ Sanitation Guidelines (2006 revision, 1997 establishment).

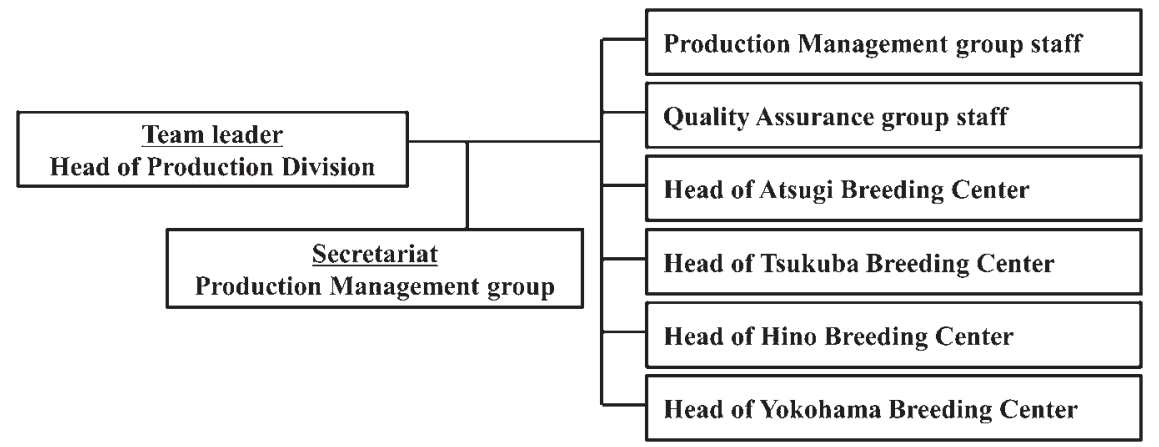

Fig. 3. Organization chart of the Task Force Team in the Production Management Division. The team consisted of the staff members in the production management and the head of each production site.

mulated guidelines [8] for business continuity and measures to prevent further spread of infection. The laboratory animal industry has also started to discuss the need to set up countermeasures against novel influenza; in particular, measures taken when a novel influenza develops into a pandemic have become imperative.

In autumn of 2008, CRLJ also started to discuss continuity of laboratory animal production in the outbreak of novel influenza, and in December 2008, a Task Force Team (Fig. 3) was set up in the Production Management Division, and guidelines for actions in case of a novel influenza outbreak (Production Dept.) (Fig. 4) were prepared.
In April 2009, a novel influenza broke out in Mexico [2], and in May, it was also confirmed in Japan [4]. In response to this, CRLJ set up a Pandemic Task Force (PTF) composed of members from relevant departments. A Pandemic Response Headquarters (Fig. 5) with six functional teams is to be set up in the case of a severe novel influenza outbreak in CRLJ or surrounding areas. In the Production Management Division, the abovementioned Task Force Team was reorganized as the Production Division Team of Pandemic Response Headquarters in preparation for a pandemic outbreak. The PTF developed and revised internal rules related to crisis management (Fig. 6), referring to official guidelines 
1. Information gathering and communication

2. Structure and organization of Production Division in emergencies

3. Internal communication and command structure

4. How to cope with infected staff and their families (living together)

5. How to deal with infection suspected cases

6. Leave of absence from work and movement

7. Cooperation with industrial physicians

8. Cautions on contact with third parties

9. Restrictions on breeding operations

10. Lift of movement restriction in terms of biosecurity

Fig. 4. Content of the guidelines for actions in case of novel influenza outbreak (Production Dept. Dec. 2008 establishment).

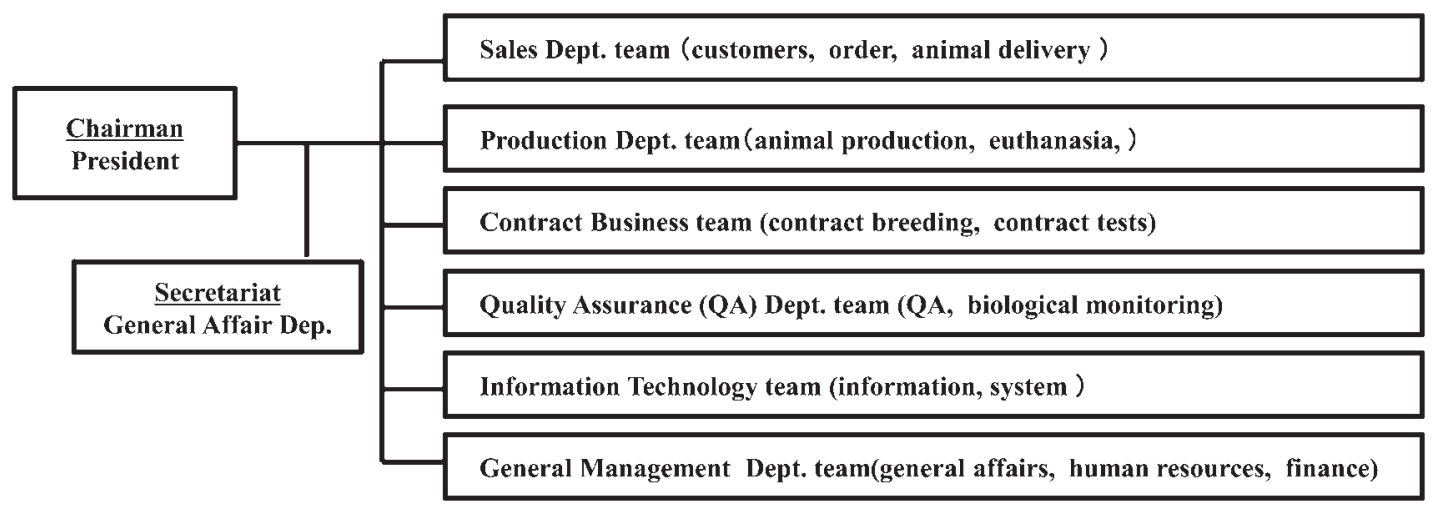

Fig. 5. Organization chart of the Pandemic Response Headquarters. The organization consisted of six functional teams to be set up in the case of novel influenza outbreak.

$[5,8]$ for novel influenza and bird flu.

Since a novel influenza was confirmed in Japan, the PTF, General Affairs Dept., and Quality Assurance Dept. have played a central role in collecting relevant information regarding novel influenza. Each month, they discussed measures to be taken as a company to address domestic and overseas expansion and to respond to the latest information in a flexible manner and announced the information below to all employees. They reviewed and updated the information and measures depending on the influenza situation. In particular, regarding business trips, CRLJ gradually and flexibly eased and tightened its internal restrictions depending on the domestic and overseas situation with regard to novel influenza.

- Enhancing awareness of each employee's sanitary management

- Ban on move or travel to a novel influenza outbreak area

- Postponement or suspension of business travel to participate in meetings including academic conferences

- Ban on overseas travel (gradually changed to 1 to 5 days suspension after returning to Japan)

- Leave of absence from work and attendance record

In the summer of 2009 , all departments were ordered 
- Regulations on risk management

- Rules to cope with a pandemic

- Guidelines for action in case of a novel influenza outbreak (Production Dept.)

- Sanitation Guidelines

Fig. 6. Guidelines, Regulations and rule for CRLJ risk management.

to come up with a BCP in order to produce and maintain a minimum volume of laboratory animals during a pandemic while securing the safety of the staff and to immediately resume production and supply of laboratory animals after the pandemic according to market needs.

The Production Management Division developed a $\mathrm{BCP}$, taking into account the lessons learned in the above-mentioned food poisoning case and simulation of an understaffed situation during a pandemic. It also simulated the case where not only the staff but also their families had a novel influenza and several staff could not work, to come up with specific measures at the site level (support from within the division or from another division, euthanasia of animals, facility closure) and to prepare for a pandemic. To continue laboratory animal production and delivery as needed even in a pandemic, we confirmed material supply, secured food stock, and checked the situation of users and delivery trucks (acceptance of animals, access limits at customer sites, etc.).

The Production Management Division reviewed the above-mentioned guidelines for actions in case of a novel influenza outbreak (Production Dept.) and the Emergency Telephone Network including local medical institutions. Moreover, mobile phones were given to supervisors and mobile PCs were given to each Plant Manager so that they could conduct some of their work from home. At each breeding center, Plant Managers distributed the following documents to familiarize the staff with the countermeasures.

- Cautions about health management of employees and their families

- Vaccination for influenza of production site employees (strong recommendation for other employees)

- Restrictions on travel and movement (participation in academic conferences, customer visits, movement to other offices)

- Access limits for visitors (postponement of visiting schedule)

- Conditions to enter animal rooms (obligation to check body temperature before coming to the production site and keep the records)

- Ban on entering the production site and attendance record (checking body temperature before coming to the site, conditions and period of special paid leaves)

- Response to cases in which staff or their families have a novel influenza

- Reports (Emergency Telephone Network, reports to supervisors, submission of medical certificates)

During the six months beginning in September 2009, 6 of 177 staff members at production sites and 49 families (living together) of staff members at production sites were affected. In each case, the staff did not come to work for about one week according to the internal rules. Compared with conventional influenza (seasonal influenza) and sudden human and animal infectious diseases, development of specific measures was not easy because novel influenzas have a lot of unknown and inexperienced aspects. Under such circumstances, various measures were taken, preventing infection spread of novel influenza, thus resulting in no direct influence on animal production.

\section{Damage to the TBC Caused by the Great East Japan Earthquake and Its Response and Issues}

CRLJ's TBC was established in 1992 in Ishioka City, close to Tsukuba Science City (Fig. 7). The center is one of CRLJ's main production facilities, with a total floor area of $3,630 \mathrm{~m}^{2}$. The facility building is a twostory reinforced concrete building with five animal rooms $\left(200 \mathrm{~m}^{2}\right.$ and $\left.300 \mathrm{~m}^{2}\right)$. Usually, around fifty animal care staff members are engaged in production of mice and rats. 
Damage to the TBC and its response

\section{Damage to the building and equipment}

At 2:46 p.m. on March 11, 2011, the TBC was hit by a great earthquake (intensity 6 lower). The epicenter was off the coast of Sanriku (Tohoku Area) (Fig. 7). Although cracks were found in the outer walls of the building and staircase, no cracks or spalling were found in the walls and floors of animal rooms, work corridors, and office rooms. No abnormalities were found in production facilities such as air-conditioning equipment, boilers, and generators. Therefore, temperature, humidity, and air cleanliness were maintained after the earthquake. In addition, no physical damage or functional abnormalities were found in indispensable equipment for daily animal care such as autoclaves, water supply facilities, and lighting. Bent and twisted parts were found in polyvinyl chloride pipes for automatic water supply, but there were no broken parts and there was leakage from joints (Fig. 8). Animal racks are connected together with bolts on their backs and sides. In addition, they are fixed by crossbars on top to racks in front of the opposite side. Therefore, no racks fell during the earthquake, although connected racks moved 10 to $15 \mathrm{~cm}$ in some animal rooms. However, 2,500 mouse cages and 1,700 rat cages fell from racks (Figs. 9 and 10), allowing 14,000 mice and rats to escape and run around in animal rooms, and we had no choice but to euthanize them.

\section{Response immediately after the earthquake}

Capture of escaped animals: Cage lids dropped off due to cages falling from racks, and many animals escaped and ran around the animal rooms. Capture of escaped animals, checking of the safety of animals left in cages, and confirmation of food and water were needed as swift as possible. However, strong aftershocks continued, and the facility manager was hesitant to let the animal care staff enter animal rooms from the standpoint of ensuring their safety. Six hours after the earthquake, the facility manager decided to let the animal care staff enter animal rooms and start recovery work. They captured the escaped animals, cleaned the rooms, checked the safety of animals left in cages that stayed on the racks, and confirmed that the animals had food and water. Recovery work continued until midnight. At 2 a.m. on March 12, recovery work was suspended for a while because the staff were exhausted, and most of the animal care staff went home. At 9 a.m., recovery work resumed, and it took until midnight to capture all the escaped animals and put the animal rooms in order. It was highly unlikely that animals escaped to outside of the facility, since they had been kept in isolated barrier rooms for the purpose of high quality laboratory animal production. However, we kept strict watch in the facility, frequently checking capture devices for mice and rats placed in corridors outside animal rooms, inside and outside of the facility, and confirmed that no animals escaped from the animal rooms.

Power supply: Although power supply was cut off immediately after the earthquake for $23 \mathrm{~h}$, there were no problems regarding air conditioning and water supply because TBC's emergency power generator functioned adequately. However, only 9801 of light oil was kept for the generator, meaning it would be used up within one day in this situation. Light oil was desperately needed from the day of the earthquake, and ultimately, 2,200 1 was secured. After that, the government decided to give priority to fuel for emergency vehicles such as police cars and fire trucks and not for other purposes such as the emergency generator of TBC. So, light oil for the generator was secured only to run the generator until the evening on March 13.

On the other hand, boilers were stopped immediately after the earthquake, since fires due to strong aftershocks were possible. Two and a half hours after the earthquake, aftershocks became smaller, and use of the boilers to maintain the environment of animal rooms was restarted. However, on one occasion, the environment was outside the standard level, showing a lower temperature and humidity. Based on the outside temperature, 2,000 1 of kerosene per day was thought to be used by the boilers. So kerosene was desperately needed, as only 6,000 1 remained on hand, and ultimately, 10,000 1 of kerosene was secured.

Drinking water: At the TBC, city water (Ishioka City water) is used as drinking water for animals. The water is pooled in a tank (capacity: $30 \mathrm{t}$ ) at the site and provided after filtration ( $50 \mu \mathrm{m}, 5 \mu \mathrm{m})$ and $\mathrm{UV}$ radiation. After the earthquake, supply of water stopped for 4 days and the tank was empty four days after the earthquake. Therefore, water from a well at the site was used as drinking water for animals. The well water was not 
murky even after the earthquake. There were no problems in a simple examination of water quality (visual observation, chloride concentration, and $\mathrm{pH}$ ) conducted immediately after the earthquake as well as in fifty items of a subsequent water quality inspection based on the Water Supply Act.

Food and bedding: The facility usually stocks a week's worth of food. The stockpiles were immediately confirmed after the earthquake. At the beginning of the next week, damage to and the stockpiles of food supply vendors were confirmed. CRLJ asked them to continue delivering food. However, it was sometimes difficult to secure means of food transport because logistical priority was given to emergency material transport for disaster areas. Four days after the earthquake, the government admitted animal food as emergency materials and the logistical problem was solved.

The TBC usually has a two week stockpile of bedding delivered from three plants. One of them is located in Ofunato (Iwate, Japan). Its bedding plant and warehouse were damaged by the tsunami, and it therefore stopped bedding production and supply. However, the TBC could secure the necessary amount of bedding from other plants.

Microbial monitoring: No damage or cracks were found in the walls, floors, and ceilings of the animal rooms. Air conditioners were not affected by blackouts, and positive pressure of animal rooms was secured. Thus, the physical barrier conditions of the animal rooms were considered to be maintained. However, many cages fell from racks, and bedding containing feces was scattered in animal rooms. The worst case scenario was the possibility of microbial infection and its spread to all the animal rooms. Four days after the earthquake, feces were collected from all strains in all the animal rooms of the TBC and sent to the Monitoring Center (Aikawa-machi, Aiko-gun, Kanagawa, Japan, it is 140 km away from the TBC) under poor transportation conditions for urgent bacteria tests through PCR and culture examination. Moreover, four weeks later, routine microbial monitoring tests were conducted as planned, and no microbial infection needing to be controlled was found in any test.

External response and resumption of animal shipment: An Earthquake Response Headquarters (ERH) was set up at CRLJ's headquarters immediately after the earthquake. Although the day after the earthquake (March 12) was Saturday, managers were called to the headquarters and gathered information concerning disaster damage including damage suffered by customers that purchased laboratory animals. We also started to discuss ways to contact research institutes such as academia and companies to provide information regarding the damage status of the TBC as well as prospects for animal production and shipment. Earthquake damage to the TBC was heavy, and blackout and fuel shortage problems were not easily solved. Therefore, ERH members started to discuss some options-euthanasia after triage of live animals, euthanasia of all the animals at the TBC, and closure of the TBC. Around 2:00 p.m. on March 12, supply of electricity was restored, and the worst-case scenario was avoided, but there were no good prospects for resumption of animal production and shipment. Learning from our experiences with the past contamination cases that we had trouble handling well and that caused confusion, we put priority on speedy and accurate communication with our customers. During the morning of March 14, three days after the earthquake, we sent messages to our customers on our emergency contact list by e-mail and facsimile to convey that the TBC was affected by the earthquake and unable to ship animals for the time being. The damage suffered by customers and their animal acceptance status were also surveyed. Taking into account the survey results, we started to develop a TBC recovery plan and its animal production plan. We concluded that research institutes could not accept animals for at least two weeks and euthanized animals that were to be shipped. Two weeks after the earthquake, we finally resumed shipment of some strains.

Supervisors and animal care staff: During the earthquake, many cages fell from racks; however, nobody was injured and all the staff evacuated safely from the facility. Most of the staff live near the facility. They were busy trying to restore their homes and getting daily necessities. Since gasoline for their cars was hard to obtain, some staff did not go home and stayed at the TBC. Under such conditions, supervisors put priority on the security of the staff and their families. On the other hand, capture of escaped animals and care of animals remaining in cages were also essential to prevent 
unexpected situations. Supervisors had been constantly required to make very difficult decision until the TBC's unprecedented situation was under control.

\section{Response to the disaster and related issues \\ ERH and chain of command}

The ERH was set up in CRLJ's headquarters to take measures for the TBC, referring to the guidelines for a novel influenza outbreak. Specifically, based on the information from the TBC by phone, the ERH discussed immediate measures to be taken and gave directions to the TBC. However, nobody from the headquarters or other facilities was able to go to the TBC to support the facility, so all we could do was discuss measures based on the limited information from the TBC. Therefore, some decisions such as those concerning capture of escaped animals, euthanasia and recovery work were left to supervisors for several days after the earthquake. Meanwhile, the ERH focused on overall recovery of the TBC, support work including customer support and business continuity.

\section{Communication tool}

At the end of 2010, CRLJ introduced an IP-PBX telephone exchange system, an internal telephone line system, to reduce communication costs and enhance convenience. Therefore, even immediately after the earthquake when most external telephone lines could not be used, internal telephone communication was never disrupted between headquarters and all other facilities including the TBC. In addition, the ERH at headquarters was constantly able to understand the damage and recovery status of the TBC by Telephone Conference and Video Conference immediately after the earthquake. This smooth communication enabled us to accurately understand the status of the $\mathrm{TBC}$, objectively analyze information sent from the TBC, and develop specific recovery plans. It also helped to support supervisors and meet their needs in various ways, without isolating them. Moreover, it allowed CRLJ to send accurate and timely messages to customers who used our animals.

\section{Building, equipment, and materials}

As noted above, the building and large equipment were not damaged. We have previously discussed countermeasures for racks and cages against earthquakes. No racks fell because they were connected with bolts on their backs and sides. At the TBC, each animal care staff member handles 600 to 800 cages in their daily work. Based on putting priority on production efficiency and work convenience, the measures to prevent cages from falling from racks were insufficient. This caused a huge amount of damages, as 4,200 cages fell from racks in the earthquake. The TBC is currently taking measures to prevent cages from falling from racks by setting up an elastic silicon belt in front of cages while also maintaining production efficiency.

Animals

During the earthquake, many cages for foundation stock of certain strains fell from racks, but foundation stock for many other strains were secured. The TBC focused on recovery work and selective husbandry for the remaining animals, considering resumption of animal shipment two weeks later. In early May, the production volume returned to normal except for two strains. Regarding the strains that lost many foundation stock animals, the production volume returned to normal at the end of July as a result of urgent import of many males and females from the Jackson Laboratory in the USA.

\section{Stockpiles}

The TBC barely overcame many difficult challenges by using its stockpiles; however, we need to further discuss our emergency stockpiles such as those of fuel, food, water, bedding, and other items. Having a large stockpile of necessities for animal care may cause problems regarding cost and space as well as various problems in maintenance. Storing fuel may go against laws such as the Fire Service Act. Cooperation with other facilities and other companies can be one of the options for emergency stockpiles in the future.

\section{Special memorial service}

At the TBC, no one got injured in evacuation and subsequent recovery work, but some of the staff showed strong anxiety when entering animal rooms because strong aftershocks continued immediately after the earthquake. Some other staff felt intense fatigue in capturing escaped animals and recovery work. In this difficult situation, they were required to promptly capture escaped animals and quickly euthanize them. Although it was hard to bring animals out from animal rooms because strong aftershocks continued, the staff managed to carry the animals to the place for euthanasia and euthanize 


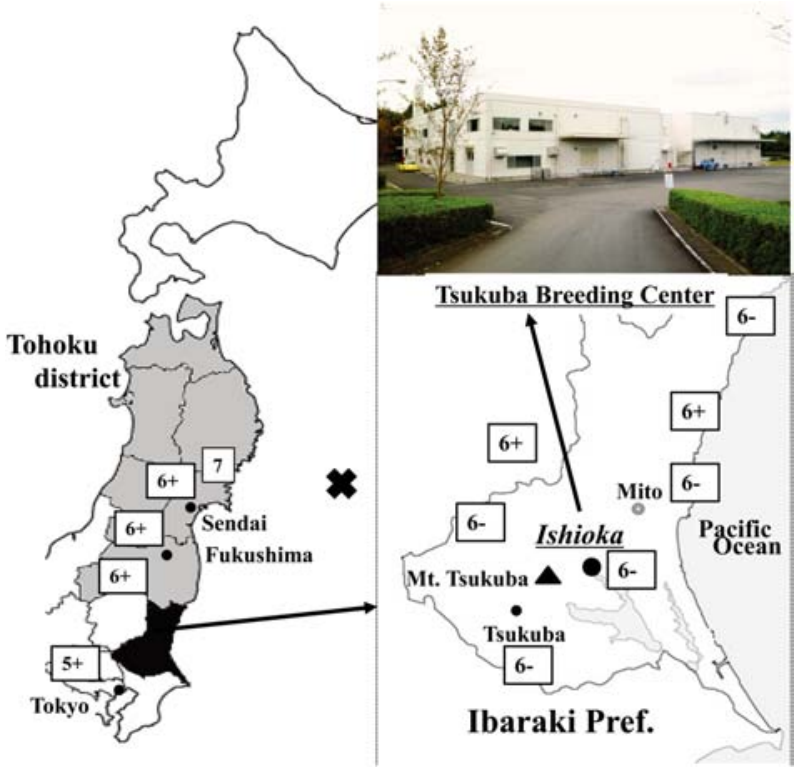

Fig. 7. The TBC is located in Ishioka, Ibaraki that is adjacent to the Tohoku district. The number shows the seismic intensity of each place, and $+\&-$ shows the strength of each seismic intensity (ex. 6+: seismic intensity 6 upper, 6-: seismic intensity 6 lower). The mark (x) shows the epicenter of the Great East Japan Earthquake.

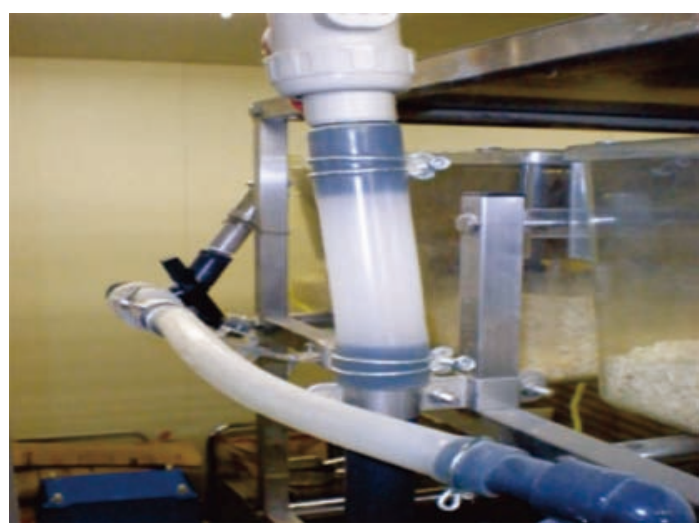

Fig. 8. A water supply pipe was bent and twisted by the earthquakes, but no breaks in pipes or leakage of water were caused.

them. That was a big mental burden for them.

Therefore, on April 6, about one month after the earthquake, a local Buddhist priest was invited to the TBC, and a special memorial service was held at the TBC memorial (Fig. 11). This service was not only for the animals euthanized due to the earthquake but also for the staff who had suffered a mental burden and was con-

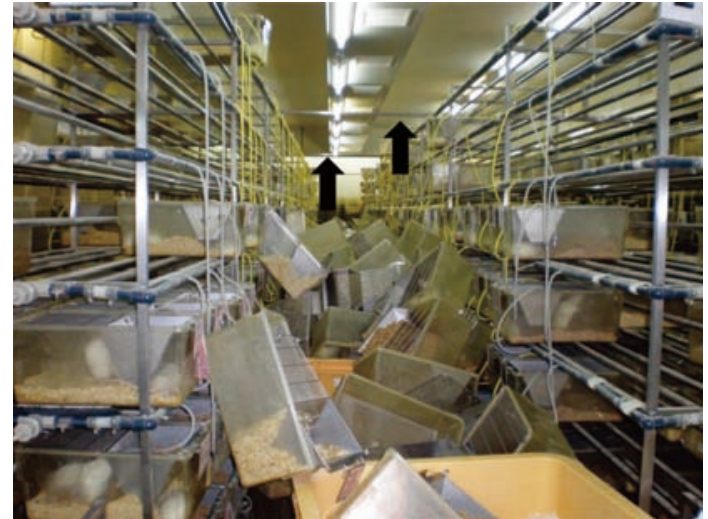

Fig. 9. TBC rat breeding room-no racks fell during the earthquake although many cages fell from the racks. Animal racks are connected together with bolts on their backs and sides, and fixed by crossbars $(\rightarrow)$ on top to racks in front of the opposite side.

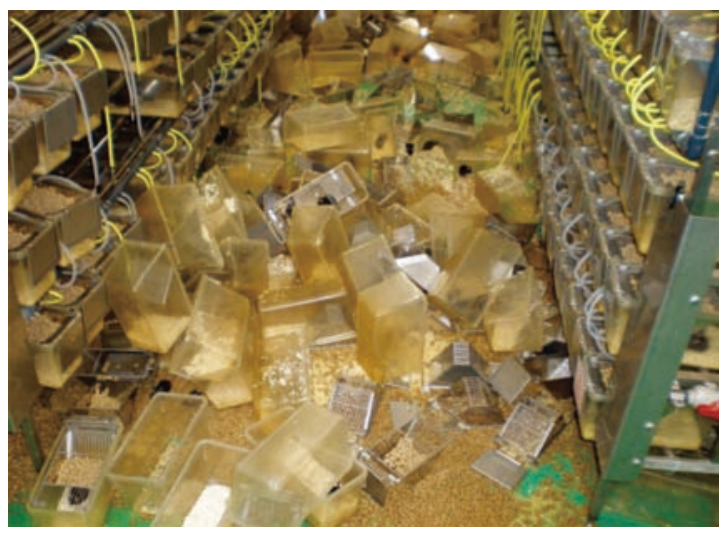

Fig. 10. TBC mouse breeding room-many cages fell from the racks and animals and bedding fell out of cages.

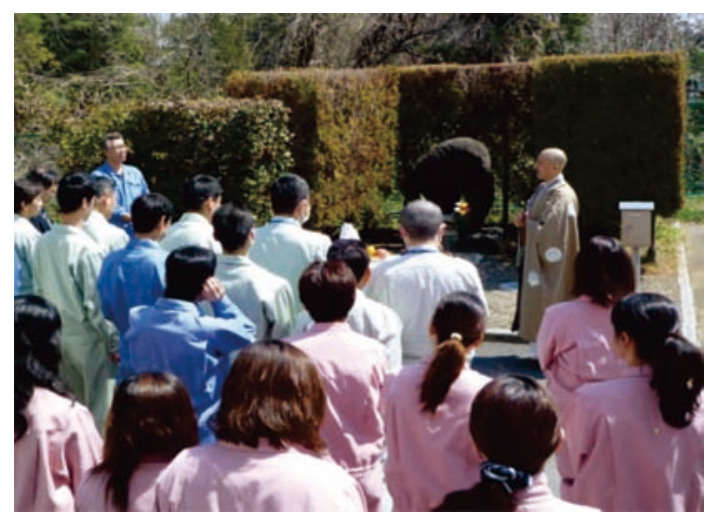

Fig. 11. A special memorial service, a Buddhist ceremony, was held in front of the TBC memorial about one month after the great earthquake. All the TBC staff members participated in the memorial and prayed for the animal euthanized as a result of the earthquake. 
ducted as a means of catharsis. Most of the animal care staff love animals and became animal care givers for that reason. Therefore, memorial services are considered to be essential events for laboratory animal facilities.

\section{Priorities for animal triage}

If the blackout had continued for another one or two hours, the supply of light oil for power generation would have been used up. In that case, it would be difficult to maintain all of the animals, and euthanasia would need to be conducted. We would also have to make assumption about significant issues. One of them is triage. We had assumed the case of animal care staff being unable to come to the facility in our discussions concerning novel influenzas, and in this crisis, we put the plans developed in our discussions into actions in triage. However, it was extremely difficult to perform triage and make efforts for recovery in the chaos after the disaster. Therefore, it is essential to prepare corporate policies and guidelines for emergencies so that on-site supervisors can judge and take actions based on them in disasters. Criteria for making decisions include such things as production status of the strain in other breeding centers, secure storage of frozen eggs and sperms, reproductive efficiency, closed colony or inbred strain and pedigree expansion stock or production stock. Setting criteria was very difficult because we had to consider complicated elements.

Disposal of animal carcasses is also an issue. We faced the problem of having to store the carcasses and find a disposal site after euthanizing a huge amount of animals. In a blackout, we have to consider how we use limited emergency power for freezing or cooling animal carcasses. We also have to consider if we can bury them without incinerating them in the case where fuel for incineration is not available. Laboratory animals produced at the TBC are free from infection, and burial was not so problematic, like burial of poultry in the case of bird flu [10]. However, we need to be careful in burying them. Fortunately, we did not actually face the abovestated two issues, but they can be extremely serious problems if a blackout and fuel shortage continues.

\section{Conclusion}

Laboratory animal facilities may face various crises such as natural disasters, human-caused crises, and physical damage. In our history of more than 30 years, we have experienced various crises and developed CMPs and a BCP. However, in the first great earthquake in 1,000 years, we faced many unprecedented crises. Our CMPs and BCP did not work as well as we had expected, and now we consider that we need to review them, but the lessons learned in our past experiences and our preparation of plans for emergencies helped us minimize damage and recover from the disaster. I experienced the Great Hanshin Earthquake in 1995 when I was a manager of an animal facility for research in Kobe, and this time, I could make good use of my past experience. In the USA, a lot of animal facilities were damaged by a hurricane in 2008 [3]. These disasters helped us strengthen our crisis management $[1,11]$. Currently, some USA websites offer information and useful guidelines for crisis management for laboratory animal experiments and facilities [7]. Recently revised guidelines issued in the USA stipulate development of a crisis management plan using the word "must" and highlight the importance of crisis management [6]. On the other hand, the Science Council of Japan Guidelines include crisis management but not in detail [9]. Specific resources for crisis management of laboratory animal facilities are not available in Japan. There is more interest in crisis management for natural disasters now. However, crisis management is needed not only for natural disasters but also for various crises such as influenza infection and threats outside the facility. Many people involved in crisis management must feel the need to review crisis management from the viewpoint of laboratory animal facility management. I sincerely hope our experiences will be a useful reference regarding crisis management for all research institutes having laboratory animals as well as for breeding facilities.

\section{References}

1. Bayne, K.A. 2010. Disaster planning and management: a practicum. ILAR J. 51: 101-103.

2. Committee of the WHO Consultation on Clinical Aspects of Pandemic (H1N1) 2009 Influenza. 2010. Clinical aspects of pandemic 2009 influenza A (H1N1) virus infection. $N$. Engl.J.Med. 362: 1708-1719.

3. Goodwin, B.S.J. and Donaho, J.C. 2010. Tropical storm and hurricane recovery and preparedness strategies. ILAR J. 51: 
101-119.

4. Infectious Diseases Surveillance Center, National Institute of Infectious Disease. 2009. Situation report on identified cases and responses in Japan-1. [Online] http://idsc.nih. go.jp/disease/swine_influenza_e/idsc_e2009/09idsc2e. html

5. International Federation of Pharmaceutical Manufacturers and Association. 2007. Pandemic influenza preparedness: Business continuity planning for the global healthcare industry. [online] http://www.jpma.or.jp/english/events/ topics/pdf/070330.pdf

6. National Research Council. 2011. Guide for the Care and Use of Laboratory Animals, 8th ed., National Academy Press, Washington.

7. Office of Laboratory Animal Welfare (OLAW). 2006. Disaster planning and response resources. [Online] http:// grants.nih.gov/grants/olaw/disaster_planning.htm

8. Pandemic Influenza Expert Advisory Committee, Ministry
Health, Labour \& Welfare. 2007. Guidelines for the prevention and control of pandemic influenza-phase 4 (phase4 onward). [Online] http://www.mhlw.go.jp/bunya/ kenkou/kekkaku-kansenshou04/pdf/09-e00.pdf

9. Science Council of Japan. 2006. Guidelines for proper conduct of animal experiments. [online] http://www.scj. go.jp/ja/info/kohyo/pdf/kohyo-20-k16-2e.pdf

10. Watanabe, O., Ishii, J., Kitagaki, T., Okawa, H., Matsumoto, H., and Kameyama, M. 2011. Logistical study in Hyogo prefecture on disposal of poultry carcasses infected with highly pathogenic avian influenza virus to prevent infection spreading to other flocks. J. Vet. Med. Sci. 73: 573-581.

11. Wingfield, W.E., Rollin, B.E., and Bowen, R.A. 2010. You have a disaster plan but are you really prepared? ILAR J. 51: 164-170.

12. World Health Organization. 2008. Wkly. Epidemiol. Rec. 83: 413-420. 